\title{
O TRABALHO DA ENFERMAGEM E A PRODUÇÃO DA SUBJETIVIDADE DE SEUS TRABALHADORES
}

Wilson Danilo Lunardi Filho*

Valéria Lerch Lunardi*

Jonas Spricigo**

Lunardi-Filho WD, Lunardi VL, Spricigo J. 0 trabalho da enfermagem e a produção da subjetividade de seus trabalhadores. Rev Latino-am Enfermagem 2001 março; 9(2): 91-6.

Para abordar as (im)possibilidades do trabalhador apresentar-se como sujeito do seu trabalho, inicialmente, focaliza-se o papel do trabalho na produção da subjetividade, no modo de produção capitalista, bem como a produção de subjetividade nas relações de trabalho e, em especial, a produção da subjetividade do trabalhador da enfermagem. Destaca-se que, no fazer do enfermeiro e das demais categorias de enfermagem, há possibilidades de organização do trabalho com espaços de criação, tanto na seqüência das tarefas a serem realizadas como no processo de sua realização, na iniciativa ou não de realizá-las.

UNITERMOS: trabalho, enfermagem

\section{NURSING AND THE PRODUCTION OF WORKERS SUBJECTIVITY}

In order to approach the (im)possibilities of workers to present themselves as the subjects of their work, authors focussed on the role of work in the production of subjectivity, within capitalism, as well as the production of subjectivity in work relations and, especially, the production of nursing workers subjectivity. They emphasized that in the work of nurses and of other nursing professionals, it is possible to organize a creative work such as in the sequence of tasks that must be performed as well as in its process of execution and the initiative to perform them or not.

KEY WORDS: work, nursing

\section{EL TRABAJO DE ENFERMERÍA Y LA PRODUCCIÓN DE LA SUBJETIVIDAD DE SUS TRABAJADORES}

Para abordar las (im)posibilidades del trabajador presentarse como sujeto de su trabajo, inicialmente, se focaliza el papel del trabajo en la producción de subjetividad, en el capitalismo, así como también en la producción de subjetividad en las relaciones de trabajo y, especialmente, la producción de subjetividad del trabajador de enfermería. Se destaca que, en el hacer del enfermero y demás categorías de enfermería, hay posibilidades de organizar el trabajo con espacios de creación tanto en la secuencia de las tareas por ejecutar cómo en el proceso de su realización, en la iniciativa o no de realizarlas.

TÉRMINOS CLAVES: trabajo, enfermería

\section{"Que possibilidades tem o trabalhador de apresentar-} se como sujeito do trabalho"? Em busca de respostas a esta questão, inicialmente, focalizamos o papel do trabalho na produção da subjetividade do trabalhador, de modo a refletir, com maior clareza e profundidade sobre o tema. Este texto, então, tem como objetivo apresentar elementos que favoreçam a discussão sobre a produção da subjetividade do trabalhador e das (im)possibilidades do trabalhador de enfermagem apresentar-se como sujeito do seu trabalho.

* Enfermeiro(a), docente do Departamento de Enfermagem da Fundação Universidade Federal do Rio Grande - FURG, Doutor(a) em Enfermagem. Endereço: Dr. Laviera, 167 - Jardim do Sol - 96216-040 - Rio Grande - Rio Grande do Sul - Brasil

** Enfermeiro, docente do Departamento de Enfermagem da Universidade Federal de Santa Catarina - UFSC, Doutorando em Enfermagem-UFSC 


\section{O TRABALHO NA PRODUÇÃO DA SUBJETIVIDADE}

Subjetivação ou produção de subjetividade são termos, preferentemente, adotados, ao invés do termo ideologia ${ }^{(1)}$. A ideologia permaneceria no âmbito da representação, enquanto que a subjetividade adentra no âmbito da modelização, estando aí inseridos os comportamentos, sentimentos, emoções, percepções, memória, relações sociais, dentre outros. Propõem a "idéia de uma subjetividade de natureza industrial, maquínica, ou seja, essencialmente fabricada, modelada, recebida, consumida"(1). Recomendam, ainda, a dissociação entre individualidade e subjetividade, já que os indivíduos decorreriam de uma produção feita em série, registrada, de massa, enquanto que a subjetividade, por sua vez, decorreria de uma construção e modelação que se dá no registro do social. Nestas modelação e produção, está compreendido tudo o que se dá no campo do social, as relações e vivências na família, na escola, no ambiente privado e doméstico. Enfim, a "produção da subjetividade constitui matéria prima de toda e qualquer produção"(1).

A subjetividade, a vida interior, as opções mais íntimas são marcadas por um ethos, em que a sociabilidade assume um tom caracteristicamente marcante. A subjetividade, portanto, desenvolve-se em função da sua interação com o grupo. É, neste espaço, que se torna possível implementar os mecanismos de sociabilidade que se mostram fundamentais para a produção da subjetividade ${ }^{(2)}$. Assim, a fabricação de um operário não se dá apenas mediante sua formação nos cursos profissionais ou no próprio trabalho, mas decorre de tudo o que se passou anteriormente, na família, na creche e na escola.

Por sua vez, a atividade profissional não é apenas um modo de ganhar a vida. É uma forma de inserção social, em que aspectos psíquicos e físicos estão fortemente implicados ${ }^{(3)}$. Mesmo que parcelar e especializado, o trabalho é imprescindivel para as pessoas, pois refere-se à sua própria sobrevivência e condicionamento social, nem sempre sendo patogênico, mas, ao contrário, detendo um poder estruturante, em face tanto da saúde mental como da saúde física ${ }^{(4)}$. 0 trabalho aparece, então, como um operador fundamental na própria construção do sujeito, revelando-se, também, como um mediador privilegiado, senão único, entre inconsciente e campo social e entre ordem singular e ordem coletiva. Não é apenas um teatro aberto ao investimento subjetivo, mas, também, um espaço de construção do sentido e significado e, desse modo, de conquista de identidade, da continuidade e historicização do sujeito ${ }^{(5)}$.

Embora 0 ato de trabalhar possua mais de uma significação, em sua grande maioria, acentuam-se os conteúdos de esforço e cansaço. Para uns, este esforço será preponderantemente físico, enquanto que, para outros, preponderantemente intelectual ${ }^{(6)}$. $\mathrm{Na}$ Antigüidade, os romanos já estabeleciam uma diferença fundamental entre dois tipos diferentes de trabalho: tripalium e $\mid$ labor $^{(7)}$. 0 primeiro designava, originalmente, um instrumento de tortura dos escravos. Com o tempo, passou a designar o trabalho escravo ou alienado, com participação quase que exclusiva e restrita do trabalhador à sua execução, portanto, excluído do planejamento e privado dos frutos de seu próprio esforço. 0 segundo era o trabalho dos livres, daqueles que planejavam, decidiam e trabalhavam no que thes pertencia, usufruindo do que produziam. Por sua vez, designava o trabalho do homem pela sobrevivência, passivamente submetido aos ritmos da natureza, às estações do ano, às intempéries.

Apesar de haver trabalho e labor, a palavra trabalho, em português, designa ambas as significações: tanto a de realização de uma obra que sirva à expressão, que garante o reconhecimento social e permaneça além da vida de quem a criou, como a de esforço repetitivo e rotineiro, sem liberdade, de resultado consumível e de inevitável incômodo ${ }^{(6)} .0$ trabalho materializa-se através do processo de trabalho que constitui-se das "condições objetivas de trabalho", ou seja, os instrumentos e materiais utilizados e as "condições subjetivas de trabalho" que dizem respeito à força de trabalho ou à "capacidade vivificadora do trabalho" ${ }^{(8)}$. Desse modo, o processo de trabalho é o canal, através do qual os trabalhadores expressam e buscam concretizar seus desejos, vontades e possibilidades, mediante o sentido e significado do trabalho construídos, em sua vida.

Por meio da produção de bens e valores que constrõem a sociedade, o sujeito trabalhador "se re-conhece, se realiza e se apresenta à sua sociedade, produzindo, portanto, não só objetos, mas uma condição que é efetivamente sua"( ${ }^{(8)}$. Dessa forma, por representar esta trajetória, o significado do trabalho perpassa a estrutura sócio-econômica, a cultura, as necessidades, os valores, bem como a própria subjetividade daquele que trabalha. Portanto, o sujeito não existe fora do contexto de sua cultura, de sua sociedade e de sua história ${ }^{(8)}$.

Segundo a leitura marxista ${ }^{(9)}$, a História, espoliando o homem de seu trabalho, desempenharia um papel negativo, quando, ao acentuar as pressões da necessidade, faz crescer as carências, coagindo os homens a trabalharem e a produzirem sempre mais, sem receberem mais do que lhes é indispensável para viver e, algumas vezes, um pouco menos. Dessa forma, o produto do trabalho acumula-se, escapando àqueles que o executam. Apesar de produzirem mais do que a parte do valor que thes cabe sob a forma de salário, oportunizam ao capital a possibilidade de comprar trabalho, novamente, "isto é, o esforço e o tempo, essa jornada que, ao mesmo tempo, talha e gasta a vida do homem" e que, 
submetido ao tempo e ao esforço, é conduzido à fadiga e, indo ao extremo, até à própria morte.

0 valor do trabalho posto à venda no mercado capitalista depende de um fator quantitativo e de um valor qualitativo, respectivamente, o tempo de trabalho e a qualificação média do trabalho. 0 fator tempo não constitui, de fato, senão um parâmetro da exploração, entre outros. Portanto, o capitalismo explora não só a força de trabalho, mas manipula, em seu proveito, as relações de produção, insinuando-se na economia desejante dos explorados, sendo os indivíduos, enquanto indivíduos, fabricados por este sistema para responder aos imperativos de seu modo de produção ${ }^{(10)}$.

\section{A PRODUÇÃO DA SUBJETIVIDADE NO MODO DE PRODUÇÃO CAPITALISTA}

0 modo de produção capitalista tem direcionado todo 0 esforço no sentido de transformação do indivíduo em instrumento de trabalho, em outras palavras, em transformar o trabalho em força de trabalho. Este objetivo vem se concretizando pela divisão da tarefa e/ou pela maquinaria, geradores de uma drástica diminuição da importância do trabalhador individual e de sua capacidade de controle ${ }^{(11)}$

Portanto, a divisão do trabalho constitui-se numa forma de organização, segundo os objetivos de valorização do capital. 0 capital, pela divisão do trabalho, consegue parcelar, desvalorizar e simplificar o trabalho individual, constituindo a primeira forma do trabalhador coletivo, criando, assim, melhores condições para sua própria valorização. A crescente fragmentação do trabalho, com vistas a sua padronização e programação, passa, necessariamente, pela redução da subjetividade, implicando perda de participação do trabalhador na concepção e execução da tarefa. Como a subjetividade do trabalhador contrapõe-se à valorização do capital, quanto menos qualificados forem os trabalhadores, maior facilidade de intervenção do capital sobre a forma de realizar as operações, sobre o tempo e precisão do processo de trabalho ${ }^{(12)}$.

Assim, a tendência evolutiva do processo de trabalho avança no sentido de fragmentar, cada vez mais, as tarefas, na tentativa de eliminar toda a exigência de qualificação e, conseqüentemente, erradicar do processo produtivo os aspectos inerentes ao trabalho qualificado. Portanto, separar as tarefas de concepção das de execução, prever e padronizar as operações de produção são formas que o capital utiliza para independer do conhecimento e experiência do trabalhador qualificado. A divisão do trabalho contribui, significativamente, para que as condições objetivas do processo de trabalho tornem-se, progressivamente, predominantes em relação às subjetivas, com vistas a um maior nível de controle do capital sobre o trabalho ${ }^{(12)}$.
Anteriormente à organização científica do trabalho, as atividades eram moduladas, repartidas, equilibradas e reguladas em função das aptidões e do cansaço do trabalhador, através da programação intelectual espontânea do trabalho. 0 método proposto por Taylor permitiu a concepção de uma organização do processo de trabalho que reduzisse e, se possível, anulasse a autonomia relativa do trabalhador nos postos de trabalho. Dessa forma, o taylorismo possibilitou à direção apropriar-se dos conhecimentos práticos, até então, monopolizados pelos trabalhadores, conduzindo à separação entre trabalho manual e intelectual. Resultou daí 0 despojamento das funções intelectuais desses trabalhadores e sua atribuição a outros agentes, reduzindo a necessidade de um grande número de trabalhadores atuando diretamente na produção. Assim, há a tendência ao desaparecimento do ofício que, ao ser substituído por funções braçais e mecânicas, exige quase nada ou muito pouco da criatividade do intelecto, tornando o trabalhador, simplesmente, uma ferramenta humana a serviço da gerência. Em outras palavras, o taylorismo, por meio da divisão do trabalho e de um minucioso programa de comportamentos, de modos de ser do trabalhador, transforma um mecanismo de serventia geral, como o homem, num mecanismo mais eficiente de serventia especializada ${ }^{(12)}$.

Por sua vez, o fordismo, ao originar a linha de montagem, procedimento coletivo de produção, interdependente e de natureza seqüencial e ao pautar-se pela integração e a fixação dos trabalhadores em seus postos de trabalho, concretiza um acréscimo considerável na intensidade do trabalho coletivo e, ao mesmo tempo, uma significativa redução na porosidade do trabalho. A redução dos tempos de produção, desse modo, atende, plenamente, aos objetivos do capital de aumento da produtividade e lucratividade. Portanto, a cadência do trabalho, passando a ser regulada mecânica e externamente ao trabalhador, permite ao capital o controle do todo, do coletivo, cabendo ao trabalhador parcelar o controle da parte que the é específica. 0 taylorismo ocupa-se da aceleração da cadência do ciclo de gestos e da redução da porosidade no coletivo e o trabalho, dessa forma, torna-se cada vez mais privado de seu conteúdo humano, tornando-se puramente repetitivo e maquinal ${ }^{(12)}$.

Desse modo, os trabalhadores não são apenas explorados economicamente, em decorrência da privação dos frutos da sinergia de seu trabalho, mas, além disso, são alienados porque, no contexto da propriedade privada dos meios de produção, também são privados da iniciativa, responsabilidade e liberdade e excluídos mesmo de uma apropriação do significado político e social de seu trabalho ${ }^{(13)}$. Por outro lado, a educação religiosa, concebendo o trabalho como um fim em si mesmo, como um valor condizente com o capitalismo e a idéia de dever profissional ou vocação, obrigam o indivíduo, na medida de seu envolvimento no sistema de relações de mercado, a conformar-se às regras capitalistas de ação ${ }^{(14)}$. 
Nos dias de hoje, o que se constata é a ocorrência da redução de todo o trabalho ao nível do labor, de esforço rotineiro e cansativo, com o único objetivo da sobrevivência. Portanto, uma laborização do mundo, bem mais do que a elevação do trabalho produtivo ao plano da praxis pela politização do operariado ${ }^{(15)}$.

\section{A PRODUÇÃO DA SUBJETIVIDADE NAS RELAÇÕES DE TRABALHO}

A subjetividade, as relações de trabalho e poder são focalizadas ${ }^{(16)}$, em um estudo de caso junto a operários dispensados do emprego, após longos períodos de convivência e aprendizagem, numa unidade fabril. Inspira-se no conceito de poder de Foucault, um poder entendido como uma rede de relações de forças que circulam entre os indivíduos, uma rede difusa sem um centro ou espaços de subordinação definidos, mas que objetiva sujeitos, relações e situações sociais, formas de sociabilidade, produzindo subjetividades. A subjetividade é entendida como o modo de ser moral do trabalhador, produzido pelo poder nas relações de trabalho. $\mathrm{Na}$ aprendizagem da formação profissional, o trabalhador também aprende o dever-ser, criando-se e construindo-se, em sua alma, forças que estimulam o espírito da disciplina no seu corpo.

As relações de trabalho, percebidas como relações de poder e não somente como relações de produção, produzem e constrõem, põem em prática uma anatomia política: a disciplina. A disciplina, como uma mecânica do poder, constitui-se em práticas que tem como objeto a dominação do trabalhador: seu esquadrinhamento, desarticulação e recomposição. Processa-se um trabalho sobre o corpo e a alma do trabalhador para que ele não apenas realize e execute o que se quer, mas que o faça como se quer, conforme as normas, as técnicas e as determinações emanadas da organização do trabalho.

A organização do trabalho nada mais é do que o exercício da vontade de quem o organizou sobre quem o executa, podendo recortar, de uma só vez, tanto o conteúdo da tarefa como as relações humanas de trabalho ${ }^{(4)}$. As relações de trabalho e de poder, então, buscam a dissociação do poder do corpo do trabalhador, a sujeição das suas forças à disciplina, criando/produzindo um aumento das suas habilidades e utilidade, concomitante ao aumento das suas forças de submissão, assujeitamento e obediência ${ }^{(17)}$.

As singularidades do dever-ser ou do modo de ser do trabalhador, construído numa rede de relações de poder, aborda, entre outras, como se dá essa construção nas relações de espaço, de tempo, da divisão técnica do trabalho, da normalização, que são, a seguir, destacadas, tendo em vista sua relevância e pertinência para a compreensão da produção da subjetividade dos trabalhadores no trabalho, de um modo geral ${ }^{(16)}$.

0 espaço do locus de trabalho é percebido entre os trabalhadores, primeiramente, como o espaço no qual se estabelecem as relações intersubjetivas, o espaço da interação e convívio construído entre si, estabelecendo-se relações de amizade e de camaradagem. Percebe-se um deslocamento e não a substituição do espaço do convívio familiar para o espaço do local de trabalho, a firma como um segundo lar, ou seja, a apropriação pelo trabalhador do espaço público como espaço privado: "os trabalhadores (re)inventam o espaço de trabalho enquanto espaço privado (familiar), sem o que não subsistiriam à inclusão de quase a totalidade de seu tempo de existência no locus de trabalho. Em sua (re)invenção criam forças em seus corpos à suportabilidade de condições de trabalho que os penalizam na longa jornada de trabalho diária e a sua acumulação no tempo de sua permanência neste locus" ${ }^{\prime 16)}$

Essa (re)invenção criativa do trabalhador, a apropriação do espaço público como privado, constitui-se em relações de trabalho que produzem a subjetividade do trabalhador, o seu modo de ser moral. Também, a distribuição dos postos de trabalho, o isolamento ou a possibilidade de movimento e circulação, de convivio, emergem do jogo de forças de determinações e conquistas, materializado na liberdade de mobilidade e/ou na fixação ao posto de trabalho, com restrições ao convivio com os demais ${ }^{(16)}$.

A tensão permanente no processo de trabalho dos dois tempos produtivos de trabalho: o quantitativo e o qualitativo. 0 tempo produtivo quantitativo constitui-se num tempo abstrato, geral, com valor de troca, enquanto que o tempo produtivo qualitativo referese ao resultado do trabalho concreto, particular, ao resultado em si do trabalho, na sua qualidade de valor de uso, que permite a expressão do seu ser trabalhador, da sua singularidade como trabalhador, conferindo significados e sentidos ao seu trabalho ${ }^{(16)}$.

Nas sociedades capitalistas, o produto do trabalho não se constitui num produto ou utilidade como numa abordagem de processo de trabalho que acentua seu aspecto qualitativo, mas o produto do trabalho constitui-se numa mercadoria com valor, um valor no qual está incorporado o trabalho enquanto tempo de trabalho abstrato e geral, ou seja, "o tempo socialmente necessário para a produção da mercadoria", um campo de tensão permanente entre os diferentes tempos de trabalho, no qual o processo de trabalho se dá e pode ser entendido ${ }^{(11)}$. A organização pelo trabalhador do seu tempo de trabalho, qualitativa e não quantitativamente, exterioriza-se na preocupação e compromisso em realizar o trabalho da melhor maneira possível, de acordo com o seu método e sistema, com respeito às suas diferenças de ritmos de tempo, lutando contra a uniformização do tempo de trabalho particular e concreto e a favor da sua humanidade, como ser humano trabalhador e não como máquina.

Contraditoriamente e associado à questão da economia do tempo ${ }^{(16)}$, foi detectada a insubmissão do trabalhador à divisão 
do trabalho, quando, recorrendo ao saber adquirido no próprio trabalho, prescinde dos desenhos da gerência técnica e, unindo as atividades do fazer intelectual com as atividades do fazer manual, constrói as peças de modo autônomo, desrespeitando a hierarquia de distribuição do saber presente na instituição. Fica claro que a divisão técnica do trabalho "persegue não a economia de tempo ou custos, mas sim uma produção de uma política de poder, cujos efeitos são a prescrição, ordenamento e regulação das condutas de cada trabalhador, o chamado desempenho, na rede hierárquica comunicacional do poder/saber, no interior mesmo desta divisão".

Por outro lado, na Administração Científica, com a introdução dos métodos tayloristas na organização do trabalho, é possível perceber o aumento de produtividade individual de cada trabalhador, mediante tecnologias que buscam sua sujeição ao funcionamento da máquina, tecnologias políticas que avançam sobre o seu corpo e a sua alma, buscando o assujeitamento das suas forças sempre mais ao sobre trabalho. Produzem-se saberes pela construção do relatório que retrata uma avaliação de sua conduta no processo de trabalho, da sua correspondência ou não à esperada produtividade, isto é, as forças do trabalhador submetem-se a um exame permanente, como objeto de conhecimento, em busca do contínuo disciplinamento ao tempo de trabalho quantitativo. Inserida nessa tecnologia, encontra-se toda uma minuciosidade e detalhamento das forças do corpo, como num assujeitamento das forças físicas às forças mecânicas da máquina: um corpo tratado como uma máquina, percebido como um conjunto de operações e engrenagens possíveis de serem calculadas, quantificadas e subjugadas $^{(16)}$.

0 poder normalizador percebido como um exercício de poder sem limites, difuso e não localizado, ocupa o espaço deixado pelas regras do direito, pelas leis. A norma busca normalizar e moralizar ao mesmo tempo. 0 trabalhador, por sua vez, como exercício de contra-poder, busca o uso das regras do direito, do contra-direito, num enfrentamento do poder normalizador, da norma. Associado, intimamente, à norma encontra-se a punição a quem dela se afaste e se rebele do que nela é preconizado, a quem busque (re)afirmar sua condição de sujeito de direitos. A punição pretende, então, "quebrar a insubmissão" ${ }^{(16)}$, das forças do trabalhador e, concomitantemente, ao ser exibida aos demais, a eles servir de exemplo, refreando possíveis rebeldias e resistências.

Parece significativo destacar, ainda que os vários espaços de resistência cavados pelo trabalhador aos enquadramentos que buscam a (re)construção do seu modo de ser, impedindo a sua apresentação como sujeito do trabalho. Podem ser percebidos espaços de exercício de contra-poder, quanto ao diferenciado e criativo uso do espaço do locus de trabalho, do uso do tempo qualitativo do trabalho, do uso da criatividade e autonomia, frente à hierarquia da divisão técnica do trabalho, do recurso à lei como a possibilidade de contra-direito de um sujeito de direitos ao uso da norma como um exercício ilimitado de quem parece deter o poder. Tais espaços denotam que o poder que busca a sujeição e 0 disciplinamento dos trabalhadores a um modo de ser moral, a um dever-ser, pode ser o mesmo poder que resiste e rebela-se a esta (re)construção da sua subjetividade ${ }^{(16)}$.

Por outro lado, o processo de desalienação do trabalhador pela apropriação do significado político e social do seu trabalho, pela sua participação na organização do trabalho, tanto na concepção como na execução das tarefas, mobilizando suas energias e capacidade de criação para a concretização de um trabalho com espaços de liberdade, responsabilidade e instâncias diferenciadas de decisão podem constituir-se em possibilidades de exercício de autonomia do trabalhador, portanto, em possibilidades desse trabalhador vir a se tornar sujeito do trabalho que executa. Entretanto, há que levar em conta que a normalização do trabalhador, a construção do seu modo de ser na sociedade, faz-se durante 0 seu processo de vida, no dia a dia, através das diferentes relações sociais, de poder, nas quais se insere, cotidianamente, desde 0 nascimento.

\section{A PRODUÇÃO DA SUBJETIVIDADE DO TRABALHADOR DA ENFERMAGEM}

E na enfermagem, como se dá a construção da subjetividade dos sujeitos que atuam nessa profissão? É relevante destacar que, na enfermagem profissional, dá-se uma formação dos sujeitos para o seu exercício, anteriormente, ao seu ingresso na profissão. Por outro lado, a enfermagem é exercida por sujeitos (auxiliares, técnicos e enfermeiros) com diferentes formações que se dão em diferentes tempos de qualificação e graus de complexidade.

Assim, o processo de trabalho na enfermagem caracterizase, predominantemente, por apresentar-se de modo que sua execução encontra-se distribuída entre os seus vários agentes, teoricamente determinada, de acordo com a qualificação exigida pelo grau de complexidade das tarefas que o compõe. Essa forma de divisão do trabalho, pautada pela qualificação, legitimada pela formação escolar, estabelece uma hierarquização de tarefas, cabendo aos menos qualificados aquelas consideradas como mais simples e, à medida que se tornam cada vez mais complexas, sendo assumidas por aqueles que possuem maior grau de qualificação, culminando com as privativas do enfermeiro. Por outro lado, tal forma de divisão exige a integração destas atividades, ou seja, seu gerenciamento que vem sendo exercido pelo enfermeiro, por ser quem detém o saber e o controle acerca de todo o processo de trabalho da enfermagem.

Há que se ressaltar que o enfermeiro, ao dedicar-se ao 
gerenciamento das tarefas desempenhadas pelos demais membros da equipe de enfermagem, apesar do controle que este the possibilita, seu raio de ação tem-se restringido, fundamentalmente, aos aspectos inerentes à concepção do funcionamento assistencial global, na unidade de trabalho, fugindo-lhe, na maioria das vezes, 0 controle sobre os aspectos pertinentes à concepção e execução de cuidados em nível individual, em posse de seus subalternos. Então, o enfermeiro, como gerente do processo de trabalho da enfermagem, exerce o controle sobre seus subordinados, porém, contraditoriamente, no exercício de tal função, assujeita-se aos desejos e ao controle da direção, em detrimento de sua própria autonomia.

$\mathrm{Na}$ formação dos enfermeiros, parece estar presente 0 discurso de formação de profissionais críticos, politizados, criativos, com capacidade de liderança e autonomia, com competência para a concepção e execução da assistência a ser prestada aos pacientes. Contudo, o que se observa, de modo preponderante, são profissionais que têm submetido e submetem-se às determinações superiores.

Há que considerar, entretanto, que no fazer do enfermeiro e das demais categorias de enfermagem existem inúmeras possibilidades de organização desse fazer. 0 trabalho em si desses profissionais permite, parece-nos, vários espaços de criação, seja na seqüência das tarefas a serem executadas, seja no processo de realização dessas atividades, na iniciativa ou não em realizá-las e assim por diante. Porém, muito desse fazer ainda vem sendo e tem sido determinado por outrem (prescrição médica, de enfermagem, determinações verbais).

\section{REFERÊNCIAS BIBLIOGRÁFICAS}

1. Guattari F, Rolnik S. Micropolítica: cartografias do desejo. $3^{\mathrm{a}}$ ed. Petrópolis: Vozes; 1993.

2. Velho G. Subjetividade e sociedade: uma experiência de geração. Rio de Janeiro: Zahar; 1986.

3. Dejours C, Dessors D, Desriaux F. Por um trabalho, fator de equilíbrio. ERA mai./jun. 1993; 33(3): 98-104.

4. Dejours C. A carga psíquica do trabalho. In: Dejours C, Abdoucheli E, Jayet C. Psicodinâmica do trabalho: contribuições da escola dejouriana à análise da relação prazer, sofrimento e trabalho. São Paulo: Atlas; 1994.

5. Dejours C, Abdoucheli E. Desejo ou motivação? A interrogação psicanalítica sobre o trabalho. In: Dejours C, Abdoucheli E, Jayet C. Psicodinâmica do trabalho: contribuições da escola dejouriana à análise da relação prazer, sofrimento e trabalho. São Paulo: Atlas; 1994.

6. Albornoz S. 0 que é trabalho. $5^{\text {a }}$ ed. São Paulo: Brasiliense; 1992. 7. Guareschi P, Ramos R. A máquina capitalista. $3^{\mathrm{a}}$ ed. Petrópolis: Vozes; 1989.
Contraditoriamente, apesar do confronto contínuo e permanente entre as determinações externas aos fazeres e às diferentes possibilidades de espaços de criação, responsabilidade e liberdade apresentados para os profissionais de enfermagem, perguntamo-nos se esses profissionais têm optado por apresentarse como sujeitos do seu trabalho ou por permanecerem objetivados na sua ação? Ou melhor, estarão esses profissionais reconhecendo as possibilidades de criação, liberdade e responsabilidade presentes no seu cotidiano profissional?

Ainda, assumindo e/ou participando da organização do trabalho da enfermagem, da sua concepção e execução, será possível considerar tais movimentos como ocupações de espaços do sujeito? Ou melhor, a ocupação desses espaços satisfaz a nossa necessidade e aspiração de sermos sujeitos do nosso trabalho? Tais mobilizações e ocupações de espaços parecem necessárias, porém, serão suficientes para o trabalhador da enfermagem constituir-se e apresentar-se como sujeito do seu trabalho?

0 trabalhador da enfermagem está imerso nas relações de trabalho entendidas como relações de poder, de forças e enfrentamentos, além de já ter sofrido um processo de assujeitamento, com diferentes intensidades, tendo em vista, a produção da sua subjetividade já iniciada, bem anteriormente, à sua formação profissional. Acreditamos que tais fatores contribuam, decisivamente, para o profissional permitir-se ou não pensar/ questionar/ocupar os diferentes espaços de possibilidades que 0 levariam a resistir, enfrentar e discordar, como expressões de contrapoderes e resistências, conquistando espaço à criatividade e permitindo-se exercer sua autonomia, enquanto sujeito.

8. Tittoni J. Subjetividade e trabalho. Porto Alegre: Ortiz; 1994.

9. Foucault M. As palavras e as coisas: uma arqueologia das ciências humanas. $5^{\mathrm{a}}$ ed. São Paulo: Martins Fontes; 1990.

10. Guattari F. Revolução molecular: pulsações políticas do desejo. $3^{\mathrm{a}}$ ed. São Paulo: Brasiliense; 1987.

11. Codo W, Sampaio JJC, Hitomi AH. Indivíduo, trabalho e sofrimento. Petrópolis: Vozes; 1993.

12. Ruas R. Efeitos da modernização sobre o processo de trabalho. Porto Alegre: FEE; 1985.

13. Motta FCP. A teoria das organizações: evolução e crítica. São Paulo: Pioneira; 1986.

14. Weber M. A ética protestante e o espírito do capitalismo. $3^{\mathrm{a}}$ ed. São Paulo: Pioneira; 1983.

15. Arendt H. A condição humana. $6^{a}$ ed. São Paulo: Forense Universitária; 1993.

16. Rosa MI. Trabalho, subjetividade e poder. São Paulo: EDUSP; 1994.

17. Foucault M. Vigiar e punir. 8ª ed. Petrópolis: Vozes; 1991.

Recebido em: 31.3.2000

Aprovado em: 7.12.2000 